PLEASE NOTE! THIS IS SELF-ARCHIVED VERSION OF THE ORIGINAL ARTICLE

To cite this Article: T. Pusa, R. Kanervo, A. Eskelinen (2017) DEVELOPING PEDAGOGICAL MODELS IN HEISE PROJECT, ICERI2017 Proceedings, pp. 597-601.

doi: $10.21125 /$ iceri.2017.0245

URL: https://library.iated.org/view/PUSA2017DEV 


\title{
DEVELOPING PEDAGOGICAL MODELS IN HEISE PROJECT
}

\author{
Tiina Pusa1, Riikka Kanervo², Anne Eskelinen ${ }^{2}$ \\ ${ }^{1}$ Aalto University (FINLAND) \\ ${ }^{2}$ Laurea University of Applied Sciences (FINLAND)
}

\begin{abstract}
The aim of this paper is to describe challenge solving processes and the development work of two pedagogical models in Higher Education Institutions for Societal Engagement (HEISE) project.

HEISE project is a three-year Erasmus+ Strategic Partnerships for Higher Education funded project that will carry out during 2016-2019. Higher Education Institutions' (HEI) play an important role in education of young people to understand the underlying value systems of society and cultures, creating abilities to foster social integration. HEISE project aims to create an innovative and attractive educational model based on experiential and challenge led learning to increase the higher education institutions' societal engagement. The aim is to promote the inclusion of disadvantaged people and encourage the participation of HEls' students. The innovation lies in engaging the owners of challenges and the students into joint teams and to use arts-based methods to understand the different point of views in solving the challenges.

The challenge solving processes are carried out by the partner institutions of the project and the best practices are collected in a toolkit for teachers to integrate challenge based learning methods into teaching. The toolkit will consist of pedagogical methods and tools, focusing on arts-based methods.

During the academic year 2016-17 challenge solving processes were organized by Laurea University of Applied Sciences and by Aalto University. The joint teams were working together and the material for the development work was collected from students' reports, the teachers' reflection diaries and the feedback of the challenge owners.

This paper will describe and analyse two pedagogical models that was defined through challenge solving processes. The paper will review the results focusing on teachers' role in the challenge solving processes. Closed pedagogical model consists of strong support by the teacher in challenge solving processes. In the open pedagogical model teacher acts more as a facilitator, who makes room for novel knowledge and action by the students and challenge owners.
\end{abstract}

Keywords: Pedagogical model, Arts-based methods, Societal engagement, Social impact

\section{BACKGROUND OF THE CHALLENGE SOLVING PROCESSES}

Higher Education Institution (HEls) need novel ways to gain knowledge and skills how to enhance intercultural understanding and a sense of belonging to a community. Thus, HEISE project aims to create an innovative and attractive educational model based on arts-based methods and experiential and challenge led learning. [1]

Social refers to human interactions and activities, and is also used in the context of wellbeing practices. Societal refers to various human activities in communities and is seen as a more encompassing concept.[2] Art can be used as a tool to influence people's thoughts, opinions and worldviews. According to the Art's Council UK (2014) there is "strong evidence, that participation in the arts can contribute the community cohesion, reduce social exclusion and isolation and/or make communities feel safer and stronger" [3].

Holden (2006) states, that art has three different value dimensions: intrinsic, instrumental and institutional value. Intrinsic value is seen as 'art for art's sake', instrumental value sees art as a tool to achieve other goals than the artwork itself and institutional value of art emphasizes techniques, structures and processes of the arts or art organizations. In arts-based methods art has instrumental value: rather than using a certain technique or reaching an aesthetic outcome, importance relies on the process. All value dimensions are important, but in this article we emphasize on the instrumental value or art. Holden states, that prioritizing one value over another does not make other aspects of value cease to exist. [4] 
Hypothesis behind both pilot projects is that using arts related methods can strengthen the sense of belonging not only on an individual level, but on the society's level [3],[5]. Social pedagogical framework, where political and pedagogical strategies overlap, was also shared in both pilots. In this frame values and meanings of human growth, societal ability, participation, emancipation, inner feeling of life control and social security create the basis [6], [7].

\section{MATERIAL AND ANALYZES}

There are six partners in HEISE project and two of them conducted challenge solving processes during the academic year 2016-17. Two separated challenge solving pilot cases were organized by Laurea University of Applied Sciences and by Aalto University and material was analyzed together. The material for the development work consider reports and reflections by students, the teachers' reflections and the feedback of the challenge owners. Three teacher-researchers established a group to create a dialogue with each other's and with material. Shared reflection made visible different pedagogical approaches, methods and duration of processes. First round with material gave distinction between two different kinds of approaches we call the closed and the open pedagogical approaches. These two material based approaches gave a structure to understand qualities in each process.

\section{CHALLENGE SOLVING CASES}

\subsection{SOLA - Mental Health Living Lab Case}

Laurea University of Applied Sciences and an association Keski-Uudenmaan Sopimuskoti ry (later Sopimuskoti) started their co-operation in spring 2015. The co-operation is called SOLA - Mental Health Living Lab. Sopimuskoti provides mental health services such as day and work activities, housing services and family work for rehabilitees and for their families. Sopimuskoti was founded by family members of mental health rehabilitees in the 1980's and it currently employs 15 social and health care professionals. Sopimuskoti's services are used by approximately 100 rehabilitees weekly.

A Living Lab is an environment where service providers, utilizers and enablers are developing services together with services' users. A Living Lab is defined as a user-driven, open innovation ecosystem which integrates research and innovation in real-life situations. [8], [9], [10] In SOLA - Mental Health Living Lab rehabilitees are co-creating and developing different kind of mental health practices and services together with their family members, workers, students and teachers. Also open innovation ecosystems activities like creation, development, validation and testing are used in SOLA - Living Lab [8], [9], [10].

During the Living Lab co-operation the students of Bachelor Programmes in Nursing, Social Services and Business have taken a part in common development work and have supported rehabilitees' and their families' well-being by organizing different kinds of group activities and workshops. Students have also supported Sopimuskoti in management, especially in question related to communication and marketing.

One of the HEISE project's objectives is to use art-based methods in various challenge solving processes. There was a need for arts-based workshops in Sopimuskoti, because arts-based methods has been seen as a tool to support rehabilitation process and strengthen the interaction skills of the rehabilitees. Sopimuskoti and Laurea's teachers agreed on the aims for the challenge solving pilot project together. The pilot project was carried out in co-operation with SOLA - Living Lab. Based on the wishes of the rehabilitees, the teachers and the workers agreed on the arts-based methods of the workshops and organized timetable. In the spring 201719 social services bachelor students took part in HEISE challenge solving pilot as a part of their Creativity and Functionality in Customer work -study unit.

The students divided into six groups and planned and carried out six different types of workshops: drama, creative writing, music, visual arts and two different workshops on physical exercise. Each workshop consisted of 4-5 sessions which were arranged about once a week. Workshops were attended by 50 rehabilitees. The main principle of the workshops was that they were voluntary. The students listened to rehabilitees' needs and resources and changed actions or applied the activities if necessary. The focus was in processes, not in methods. That's why we can say that the content of the 
workshops were planned partly together with rehabilitees. The students made the preliminary plans that were developed together in the workshops.

The lecturers supported the students' learning by making the processes as clear as possible. Timetables and topics of the workshops had been agreed in advance with Sopimuskoti's workers. At the beginning of the process there was also a common visit to Sopimuskoti with the students, during which the students had the possibility to ask and agree things together with the rehabilitees. It was agreed that each workshop would have an employee supporting the work of the students and the rehabilitees.

During the pilot project students took part in lectures that supported their professional growth. Themes of these lectures consisted of ethical issues, the importance of positive feedback, the guidance and impact of art-based methods. There was also the final seminar where the students and the rehabilitees presented together what they had done during the art-based workshops.

According to rehabilitees' and students' feedback workshops created positive impact. The students learned a lot about guidance of arts-based methods in practice. Working with the rehabilitees helped the students to interact in different kind of situations and opened their eyes to understand mental health problems. Rehabilitees had an opportunity to participate in various workshops. Through creative activities it was possible to express themselves in various means and to interact with other people through drama, music, movement, painting and writing. They supported and encouraged each other to take part and try out new things. Doing things together created joy and strengthened the feeling of belonging not just to the surrounding community, but to the society as whole.Please, do not number manually the sections and subsections; the template will do it automatically.

\subsection{Harju Case}

During autumn 2016 Aalto University's NoVA (Nordic Visual Studies and Art Education) MA students collaborated in small groups with four institutions. One group of three students collaborated with Youth Work of Helsinki City in Harju Youth House is situated in Kallio. Harju's profile is to combine music and visual art activities.

Beside learning goals there has been challenge based project setting. At the first students made a site visits to meet people involved to the site. Through monitoring and discussions students framed the challenge and conducted project for to solve the problem. NoVA students piloted Challenge Framing templates for HEISE during their project works.

Collaboration with Harju was intervention based collaboration. In very beginning of collaboration students find out that intervention is not the best way to approach this site. Students were astonished how well everything already were in Harju. Students decided to follow up and in a way "melt" to the community. During process student group analyzed strengthens of Harju community.

To make strengthens visible the group planned an exhibition and an event to make young Harju artist seen and Harju easy to visit. Event made possible NoVA students to meet young Helsinki citizens and enjoy their art. Harju staff was very pleased and based on this first shared experience they were willing to continue collaboration with NoVA program. In report made by students it was mentioned that this was the first event combined with musicians and artists in Harju. Also according to the student report one employee said that this was the first research approach in Harju that does not use the technical approach.

\section{THE TEACHER'S ROLE IN DIFFERENT STAGES OF THE PROCESS}

The teacher has different kind of roles and tasks during the challenge solving processes. The teacher organizes, develops and evaluates co-operation with partners, other teachers and students. The teacher has to fit the challenge solving processes to study units or project work. Based on the two challenge solving pilots we defined three stages of pedagogical process where the teacher has to act: starting stage, action stage and evaluation and reflection stage.

In the starting stage the teacher makes advance work and starts co-operation with a partner organization and organizes a preliminary meeting with a partner. It is important to make a tentative agreement on collaboration and clear the process for the partner organization beforehand. The teacher gives learning frame and introduction of partners for the students and figures out learning needs and students' aims before the first common meeting. It is important to define what societal 
means in this project contexts. The teacher's role is to facilitate the first common meeting with students and partners and guarantee ethical approach to the project. Good communication, documentation, trust and commitment are basis for cooperation so that the students and partners are encouraged to act and think out of the box in challenge solving process.

In the action stage the teacher's role can be different depending on a study units targets and the level of studies. A teacher can work as a mentor, a supervisor, a manager, a facilitator or as a supporter. It is important to clarify to oneself and to the students what kind of role the teacher has. The target is to face the students with something new in a challenge solving process. Learning can be seen in clarifying problems and conflicts or solving challenges together. Like in all creative processes the product shouldn't be the outcome but the dialogical process with the people. The teacher's task is to check the aims and goals if needed and notice slow changes and small signals. This support can be organized by follow up meeting with the whole group or with each team. The students' teams can also support each other's by mutual learning, peer learning or giving new perspectives during action. Naming phenomenons and issues which appear during processes deepen students' expertise.

In the evaluation and reflection stage the evaluation should be done together with partners, students and the teacher. The students' role is to collect feedback and evaluation materials during the process and use different ways of documentation if it is possible. Good evaluation and facing outcomes helps to continue co-operation with partners and it also helps students' in reflecting the learning outcomes. For students' point of view they can combine learning outcomes to their career plans and professional growth and competences. Summarizing the challenge solving process and scaling it into the wider context with the help of the teacher gives good bases to plan for the next step in one's studies and future career path.

\section{CONCLUSIONS}

According to the challenge solving pilot cases we can define two pedagogical models, closed and open, where the teacher acts in different ways during the three stages of the process. The SOLA Mental Health Living Lab Case can be seen as an example for the closed model and the Harju Case as the open model. Both models are built on social pedagogical framework that emphasises the importance of community in human development. Social pedagogical approach pays special attention to the pedagogic meaning of people's spontaneous common action within a self-governing community [11].

At the starting stage in the closed model the teacher's orchestration was based on the learning objectives of an existing course. Also the co-operation with the partner had started earlier and the challenges and aims for the collaboration were defined beforehand. The learning environment was structured and the teacher was a conductor of the process. In the open model the teacher started cooperation, but the students had more active role to collaborate with the project partner and to find solutions to challenges through monitoring and joint discussions.

In the action stage the students in both models were working in challenge solving processes using artbased methods. In the closed model there were lectures and guidance for the students and the cooperation with the students and the partner took place only during the workshops. In the open model students' role was wider and they were responsible for organising meetings and co-operation as a whole.

The importance of common final discussion with the students and the partners in the evaluation and reflection stage was raised up in both models. This is a stage where you can conclude the cooperation and there is an opportunity to hear each other and give mutual feedback. For the students, the challenge solving projects were not only seen as learning processes to gain credits, but an opportunity to learn more about the society and to develop professionally. In both cases the art-based methods were seen as activities to promote wellbeing and to create interaction and sense of belonging to the community and the society for those who participated the cases.

Finally, differences between the closed and the open pedagogical models appear mostly in the action stage. In closed model strong support by the teacher, for example assignments and guidance discussions during the process, is essential. In the open model the teacher acts more as a facilitator, making questions and encouraging students in their path. As a conclusion we can state, that both models share the social pedagogical idea of an educative community as a basis of individual and social development [6]. 


\section{REFERENCES}

[1] HEISE project, Higher education institutions for societal engagement, Accessed 26 September 2017. Retrieved from http://www.mapsi.eu/heise/

[2] R. Anttonen, V. Ateca-Amestoy, K. Holopainen, T. Johansson, A. Jyrämä, A. Karkkunen, K. Kiitsak Prikk, K. Kuznetsova-Bogdanovitš, M. Luonila, JM. Kõlar, B. Plaza, K. Pulk, T. Pusa, A. Ranczakowska-Ljutjuk, M. Sassi, I. Stiller and A. Äyväri, Managing Art Projects with Societal Impact. Helsinki: Unigrafia Oy, 2016.A.A. Author, Book Title. City/State: Publisher, Year of Publication.

[3] Arts Council England, The Value of Arts and Culture to People and Society. An evidence review. Retrieved from http://www.artscouncil.org.uk/sites/default/files/downloadfile/Value_arts_culture_evidence_review.pdf 2014.

[4] J. Holden, Cultural value and the Crisis of Legitimacy Why culture needs a democratic mandate. London: Demos, 2006.

[5] P. Känkänen \& M. Bardy. Life stories and arts in child welfare: enriching communication, Nordic Social Work Research, 4:1,mpp. 37-51. Retrieved from http://dx.doi.org/10.1080/2156857X.2013.781536. 2014.

[6] J. Hämäläinen, Social Pedagogical Eyes in the Midst of Diverse Understandings, Conceptualisations and Activities, International Journal of Social Pedagogy, vol. 1, no. 1, 2012.

[7] J. Hämäläinen, Hyvinvoinnin kaksi strategiaa: poliittinen ja pedagoginen. In P. Niemelä \& T. Pursiainen (eds.) Hyvinvointi yhteiskuntapoliittisena tavoitteena. Sosiaalipoliittisen yhdistyksen tutkimuksia nro 62. Kuopio: Kuopion yliopisto, pp.16-29, 2006.

[8] S. Leminen, Living Labs as Open Innovation Networks. Networks, Roles and Innovation Outcomes. Doctoral dissertations. Aalto University Department of Industrial Engineering and Management, 2015.

[9] A. Ståhlbröst and M. Holst, The Living Lab Methodology Handbook. A Transnational Nordic Smart City Living Lab Pilot - SmartIES, 2012.A.A. Author, "Chapter Title" in Book Title (Editors eds.), pp.-pp., City/State: Publisher, Year of Publication.

[10] S. Heikkanen and M. Österberg (eds.), Living Lab ammattikorkeakoulussa. Ammattikorkeakoulujen neloskierre - hanke, Haaga-Helia ammattikorkeakoulu, 2012.

[11] J. Hämäläinen, Defining Social Pedagogy: Historical, Theoretical and Practical Considerations, The British Journal of Social Work, vol. 45, Issue 3, pp.1022-1038, 2015. 